\title{
¿Analogía entre estética y política? Génesis simbiótica
}

\section{Analogy between Aesthetics and Politics? Symbiotic Genesis}

\author{
María Rosa Palazón Mayoral \\ Instituto de Investigaciones Filológicas \\ Universidad Nacional Autónoma de México
}

\begin{abstract}
Resumen: Remontándose a Sócrates y el ágora, Hannah Arendt piensa que ahí estuvo la primera democracia. Treinta años después de Pericles, Sócrates fue asesinado. En Las Leyes, Platón limitó la política a las élites filosóficas y negó la democracia y la persuasión. Sin voluntad expresa de unir el gusto con política y democracia, Kant, en su tercera crítica, retoma el juicio reflexionante o del gusto y cree que, por su veracidad, espontaneidad y búsqueda de comunidad basada en el gusto, es la clave para la política: si uniéramos el sentimiento y la percepción en el juicio del gusto, aceptaríamos que tiene facetas que sirven a la filosofía política. Ricœur discrepa en que la política pueda ser idea sin fin, aunque alaba la ejemplaridad de la experiencia estética que se manifiesta en el juicio del gusto. Para Lyotard tal juicio es el "como si", que universaliza el gusto (que llama entusiasmo).
\end{abstract}

AвSTRACT: Going back to Socrates and the agora, Hannah Arendt thinks the first democracy was there. Thirty years after Pericles, Socrates was killed. In Laws, Plato limited politics to philosophical elites and denied democracy and persuasion. Without an expressed willingness to unite taste with politics and democracy, Kant resumes, in his third critique, the reflective judgment (or judgment of taste) and believes that, because of its truth and spontaneity and due to its taste-based search for community, it is the key to politics: if we joined feeling and perception in the judgment of taste, we would accept that it has facets that serve political philosophy. Ricœur disagrees with the conception of politics as an endless idea, although he praises the exemplary nature of the aesthetic experience that manifests itself in the judgment of taste. For Lyotard such judgment is the "as if" that universalizes taste (which he calls enthusiasm).

PAlABRAS ClAVE: gusto, comunidad, política, democracia, veracidad.

KEYWORDS: taste, community, politics, democracy, veracity.

RECIBIDO: 25 de enero de 2016 • ACEPTADO: 1 de noviembre de 2016 
María Rosa Palazón Mayoral

Instituto de Investigaciones Filológicas

Universidad Nacional Autónoma de México

\section{¿Analogía entre estética y política? Génesis simbiótica}

¿Cómo podemos ser miembros de una polis y actuar y dialogar al margen de la política?

HaNnAh ARENDT (2008: 144).

En La promesa de la política, Hannah Arendt intenta extrapolar el juicio reflexivo a la política, siendo ésta una particularidad de la humanidad que puede vivir en una polis, y cuya organización depende de una forma de convivencia (politikón). Quizá se equivoque, pero consigna que durante los treinta años que separan la muerte de Pericles y el juicio de Sócrates estallaron tales conflictos en los que se derrumbó la filosofía política en la apolítica, o indiferencia por la ciudad. En ese entonces Platón (véase Las leyes) pierde su fe en la polis al tenor de las enseñanzas socráticas, según las cuales, igual que el juicio del gusto, la creencia política no es concluyente, nunca obliga a los demás a una y misma conclusión, al mismo asentimiento, sino que tan sólo persuade, peithen. Contra la persuasión, el resentido Platón acuñó una forma de discurso filosófico, la dialegésthai. Si hubiera persuasión, que no es el caso, sería entre dos, nunca entre una multitud. Su maestro no convenció a los jueces de acusaciones falsísimas. La diosa de la persuasión, Peitho, con templo en Atenas que enaltecía, era una mera fantasía. La democracia había llegado al principio de su fin, esto dice que los hombres libres (no las mujeres ni los esclavos, encargados del trabajo para que sus amos pudieran ocuparse de la política y de las orgías, entre otras actividades) 
conversaban discursivamente y sin coacción en el mercado. En El Critón, Sócrates ya sentenciado argumenta que podría huir para no padecer la pena de muerte. Realmente la sufría por razones políticas, a saber, hablar de las mejoras de la ciudad y actuar en correspondencia con sus connacionales o paisanos libres.

La opinión sobre lo público significaba resplandor y fama, relacionada con el espacio político, con la bella comunicabilidad. Aristóteles comenzaba su filosofía política con una pregunta sobre la doxa ajena para no ignorar lo que opinaban los otros y enjuiciar si atinaban, y para enriquecer su propia doxa. La conversación no precisa conclusiones, pero al menos afianza la comunicación, la convergencia, la proximidad entre los ciudadanos, en varios aspectos desiguales y en otros diferentes. De suerte que la comunicación nace de la comunión que iguala en pensamientos. Para igualarse es menester que se diga verazmente la propia doxa, iniciando por estar de acuerdo con uno mismo. El ciudadano que se contradecía era porque su idiosincrasia estaba cerca del totalitarismo.

La polis era para los griegos de entonces el espacio público-político donde los hombres alcanzan su humanidad plena (Arendt 2008: 5).

Una pluralidad de sentidos para el mundo que habitamos en común ajusta los datos particulares e idiosincráticos al espacio del que participamos y que compartimos entre todos (Arendt 2008: 78).

Sólo de la libertad y del diálogo, no con uno, sino con muchos, puede emerger un mundo visible que interactúa desde lo más cercano al sí mismo hasta la universalidad, pensó Sócrates.

La política supone la libertad que aportan los oasis vivificantes o el gusto espontáneo en la naturaleza, las artes, el amor, la amistad y en cualquier acción y teoría en el espacio que se habita.

La política no es definible, tampoco el gusto, porque son categorías de la razón que invitan a ser mejores ciudadanos respecto al otro, a reverenciarlo (sin definir la reverencia, apostilla Jerome Kohn) (Arendt 2008: 37). El amor y el gusto son imposibles de fijar teóricamente. En Grecia se hacía gala del gusto por lo bello en la polis, en la naturaleza, en la escultura, la pintura, la música, la poesía... A diferencia de un juicio del gusto, la belleza de la praxis de las acciones difiere respecto a lo bello y lo no bello, no tanto por ellas mismas como en función del fin por el cual son emprendidas. "Dondequiera que los hombres coinci- 
den se abre paso entre ellos un mundo que es ese 'espacio entre' donde tienen lugar los asuntos humanos" (Arendt 2008: 143).

Cuando se sentenció al gran Sócrates, a la ciudad le sobraba, según sus gobernantes, un filósofo mayéutico encandilado por las doxai de los ciudadanos. La vieja ágora, nuclear en los gobiernos democráticos, no era ya del pueblo, sino de las élites, para las cuales poco o nada vale el demos, es decir, el pueblo formado por las clases medias bajas. En manos de unos pocos intelectuales, conocedores de la Verdad, se ha ido rompiendo la comunidad democrática: faltaban la pasión y la sensibilidad socráticas y de Isócrates. El panorama se oscurece cada vez más, de manera exponencial, hemos llegado a las tiranías, a la tecnología de bombas y a comprar y tirar, a las proverbiales dictaduras latinoamericanas, a dos guerras mundiales y a la destrucción ecológica. Las acciones y las máquinas nos están conduciendo quién sabe dónde (Arendt 2008: 27), ¿a la destrucción de la Tierra? No parece una idea descabellada, porque la economía (con sus usos de la química) y la política han erosionado el mundo. Los ojos se cierran a lo que ocurre, otros escapan para internarse en el baldío de ideas y actos.

La existencia se acompaña de males a resolver; empero, a medida que avanzan los relojes, las tiranías disfrazadas se apoderan de más espacios planetarios donde "todo se vale" (Arendt 2008: 41). La falta de límites, la injusticia flagrante, el hambre, los presos políticos...

Platón denunciaba los males que acarrea la castrada opinión, por atinada que fuese. Existe la Verdad que no es irresponsable. Los criterios absolutos de cuño abierto, de figuras o esencias inmutables de raíz matemática, eran los absolutos con que se juzgaba la política, con la confiabilidad que solo llevaban a cabo los filósofos de la Academia. La doxa moi, lo que me parece, no fue para Platón el eikós aristotélico: lo probable, la verosimilitud.

Kant recibe la inspiración socrática: el juicio del gusto no es un juicio determinante, o acto predicativo que, partiendo de la regla, aporta un caso, lo que le confiere objetividad. El gusto es reflexivo porque no se atribuye ninguna objetividad, sino que manifiesta la reacción del gusto, la función estética que se expresa así: "X es bello" o "X me gusta".

Kant parte de una reacción universal y de una constancia indiscutible, lo que garantiza la universalidad del juicio, su discriminación de lo 
feo o asqueroso, su apego a lo particular, y un libre juego entre imaginación y entendimiento que escapa al juicio intelectual y moral. Tiene una finalidad sin fin ( $\$ 10$ de la Analítica de lo bello). Lo fundamental del gusto es la comunicabilidad (Ricœur 1999: 142). Nadie se casaría con alguien de gustos radicalmente opuestos a los suyos, ni siquiera lo aguantaría como amigo. El gusto surge de una reacción íntima que se atribuye universalidad, que se encamina a la comunidad mediante tal reacción que, además, valora al estímulo como un todo formado por partes no cambiables (un holón), porque si alteras una parte, alteras el todo.

Platón había introducido la Verdad con mayúscula, donde no caben las doxai. Lo abstracto esencial hizo su acto de presencia. Decía: la política se ejecuta en el ágora, además de simples opiniones que la concretan mal, son, también, pasión que no tiene los ojos abiertos a la fragilidad humana. Incluso los sabios no partidarios de este idealismo ignoraban lo que es bueno para sí, en tanto no giraban hacia lo no humano, a la razón, a lo eterno o inmutable, que no existe, sino que subsiste. El agathós era el bien absoluto, no para mejorar instituciones inestables y accidentales, el bien no era reductible a opiniones sobre instituciones vigentes. Era indispensable remontarse hasta las esencias, si se era realmente un sabio gobernante. Respecto al ideal del kalón k'agathon (lo bello-bueno), Platón se decide por el Sumo Bien. Como amante de lo inmutable y lo racional no pierde el tiempo en las cosas bellas por imitación, siempre discutibles. Lo bueno ilumina, lo bello solamente brilla; el primero ambula en la inmortalidad.

Enfrentando lo que es hoy la política, un espacio socavado por caminos subterráneos, sótanos y alcantarillas (Arendt 2008: 78), surge la pregunta si tiene algún sentido (Arendt 2008: 145) gastar el discurso en ella. Volver a la esfera de lo particular es hundirse en el idion, en la limitación y la idiotez. "Si entendemos por política algo que esencialmente [...] ha nacido en la polis y continúa unido a ella, se da la contradicción interna que suprime y arruina lo especialmente político" (Arendt 2008: 176), cuyo cumplimiento exige el sacrificio de la soledad. Tal violencia de replegarse en la interioridad debería proteger la vida de las amenazas de destrucción ecológica y de la creatividad, no es así.

La nueva filosofía política, para Ricœur, no está limitada al entusiasmo del gusto que se genera de golpe, espontáneamente, inicialmente 
sin conceptos. Una aclaración, la actualmente llamada "función estética" no excluye las funciones prácticas y teóricas del estímulo, sino que inicialmente las pone en un lugar oculto, no se ven, están como si no estuvieran, según Lyotard, tal es la fuerza del gusto o del entusiasmo, pues el gusto es un entusiasmo sin fin, alejado del interés mercantil o político o de cualquier índole. Sobreviene cuando menos se espera: las tareas que se atribuyen al estímulo, lo opacan; por ejemplo, estudiar una novela por la manera que eleva lo particular a lo universal.

Por supuesto que, a juicio de Hannah Arendt, la vida es producir(se), lo cual supone renovación para rejuvenecer el desierto mediante el amor mundi, desierto al que vamos con botas cada vez menos de siete leguas. "La historia tiene muchos finales y muchos comienzos, y poniendo en cada uno de sus comienzos un final que no había antes" (Arendt 2008: 80). La archein comienza a dominarnos si analizamos el significado originario de la política. El agere pone algo en marcha, desencadena un proceso. Para Arendt pudiera surgir una nueva filosofía política (tal es su retrospección para el futuro). Este problema que se halla cada vez más a la orden del día. "Está en la propia naturaleza de una tradición ser aceptada y absorbida, y por así decir, por el sentido común, el cual ajusta los datos particulares e idiosincráticos de los otros" (Arendt 2008: 75). Son reacciones fuera de lo normal que, si se acompañan de coraje, libertad que no imita y de doxa verdadera, son tan ejemplares que resulta tentador aplicarlas a la política. Apela, además, a continuar la propia reacción sin servilismo (Ricœur 1999: 143). Esta paradoja se amplía en la kantiana "Analítica de lo sublime”, dinámico (no negativo o acontecimientos monstruosos de la historia), el que exalta el juego tranquilizador, discordante, y que ensancha el juego de facultades, donde la imaginación es atrapada por lo absolutamente grande o fuera de comparación.

Entregándose al gusto, el genio crea mejor. Gusto y creador son ponderados para la política como signos, síntomas e indicios de esperanza, escribe Ricœur en su octava proposición: las retrospecciones socráticas y kantianas se vuelven prospectivas y proféticas (Ricœur 1999: 148) contra la insociable sociabilidad.

La pluralidad constante de experiencias estéticas y emisiones del juicio del gusto, más su veracidad, su coraje, su riesgo asumido en busca 
de la comunicación análoga y solidaria, o sensus communis, no bastan. Para Ricœur, las anteriores cualidades ponen en relieve que no se garantiza la esperanza de todos, sino la ejemplaridad del estímulo. Sólo que la ejemplaridad del pasado no puede ser una expectativa utópica sin una teleología subyacente: "La esperanza aparece en Kant [y Arendt] como un puente lanzado entre la mirada del testigo y la espera del profeta" (Ricœur 1999: 152). Termina nuestro hermeneuta diciendo que "El único indicio de reconocimiento para la filosofía crítica: la ejemplaridad que da una cabalidad y, por este rodeo", la dimensión profética del juicio reflexivo mismo (Ricœur 1999: 155).

Sócrates, Arendt, y Ricœur tienen otro compañero de inquietudes, a saber, Jean-François Lyotard, quien dice: Kant no lanza una doctrina, sino la entrega a lo crítico (que ejerce el juez que examina los juicios cuya autoridad no deriva de algo, sino que le asiste), que cuando juzga con los sentimientos usa el "como si". No encuentra legislaciones, sino que por dondequiera la imaginación juzga sus reacciones, no mediante una regla de presentación directa, sino indirecta, que ofrece un juicio correcto que muestra su capacidad unificadora de las facultades o archipiélago disperso. Cada una es una isla; un almirante lanzaría de una a otra isla expediciones que presentarán lo común que encontraron en otra isla, que sirve "como si" para validar el juicio del gusto, ilustra Ricœur. Otro tema es la reflexión entre lo bueno y lo bello, a saber, la inmediatez, sin interés comercial ni petulancia: libertad y universalidad. La sensación parte y se agota, dice Lyotard, en la inmediatez. Pero la sensación estética trascendental o del gusto sí es un símbolo de lo bueno gracias a lo bello.

Lo sublime en la historia es lo bueno cuando entraña un disgusto, un miedo, apresado por medio del dolor. El entusiasmo es un modo de lo sublime por medio del dolor superado, que requiere un sentido comunitario, un consenso indirecto. "Síguese de ello que la universalidad a la que apelan lo bello y lo sublime es solamente la idea de comunidad para la que sólo caben presentaciones indirectas" (Lyotard 2009: 89).

El asunto es complicado y entusiasmante si, y sólo si, la función estética esconde las demás funciones, y si la humanidad es capaz de presentarse en varios tiempos después de haber resuelto, o intentado resolver, los problemas teóricos y prácticos de ciudades o polis. Lo más 
solidarios posibles para que la voz de la democracia vuelva a ocupar una cima en nuestra época.

\section{Bibliografía}

Arendt, Hannah (2008). La promesa de la política. Ed. e intro. Jerome Kohn, trads. Eduardo Cañas y Fina Birulés. Barcelona, Paidós (Paidós Básica, 149).

Lyotard, Jean-François (2009). El entusiasmo. Crítica kantiana de la historia. Alberto L. Bixo/Trad. Barcelona, Gedisa Editorial (CLA-DE-MA. Filosofía).

Ricoeur, Paul (1999). Lo justo. Trad. Agustín Domingo Moratalla. Madrid, Caparrós Editores (Col. Esprit, 34). 